\title{
Histological Mechanisms of the Resistance Conferred by the Ma Gene Against Meloidogyne incognita in Prunus spp.
}

\author{
Samira Khallouk, Roger Voisin, Cyril Van Ghelder, Gilbert Engler, Saïd Amiri, and Daniel Esmenjaud
}

First, second, third, fourth, and sixth authors: INRA, UMR Interactions Biotiques et Santé Végétale, UMR INRA 1301, CNRS 6243, and Université de Nice Sophia-Antipolis, F-06903 Sophia-Antipolis, France; and fifth author: Ecole Nationale d'Agriculture, Département de Protection des Plantes, 50000 Meknès, Morocco.

Accepted for publication 18 March 2011.

\begin{abstract}
Khallouk, S., Voisin, R., Van Ghelder, C., Engler, G., Amiri, S., and Esmenjaud, D. 2011. Histological mechanisms of the resistance conferred by the Ma gene against Meloidogyne incognita in Prunus spp. Phytopathology 101:945-951.

The $M a$ gene from Myrobalan plum is a TNL gene that confers a highlevel resistance to all root-knot nematodes of major economic importance, including Meloidogyne incognita, M. javanica, M. arenaria, and M. enterolobii. The nematode behavior in the roots and the corresponding histological mechanisms of the $M a$ resistance to $M$. incognita in the resistant (R) accessions of the plum 'P.2175' and the interspecific hybrid P.2175 × almond-peach ' 35 ', carrying the Mal allele (Mal/ma), were characterized in comparison with the susceptible (S) accessions in the plum 'P.2032' and the interspecific hybrid P.2175 $\times$ almond-peach '253'

gated plantlets grown in soil substrate under controlled conditions at $25^{\circ} \mathrm{C}$. Nematodes penetrated both $\mathrm{R}$ and $\mathrm{S}$ plants preferentially along the apical zone or close to the young lateral buds and moved via similar routes. Then they migrated into the cortex downward in the direction of the apex and turned up in the meristematic apical region to colonize the differentiating stele. In $\mathrm{R}$ accessions, motile $\mathrm{J} 2 \mathrm{~s}$ neither swelled nor developed into $\mathrm{J} 3 \mathrm{~s}$, and initiation of feeding sites was never observed. This complete absence of gall symptoms is associated with cell necroses and corresponding hypersensitive-like reaction (HLR) phenotypes occurring either in the stele or in the meristematic apical region or in the cortex. Nematode attacks often disorganized the meristematic apical tissues of $\mathrm{R}$ accessions, which induced the development of subterminal lateral roots replacing primary terminal apices and, thus, provided an active resistance reaction to HLR damage.
\end{abstract} $(\mathrm{ma} / \mathrm{ma})$. Second-stage juveniles (J2s) were inoculated in micropropa-
Root-knot nematodes (RKNs) (Meloidogyne spp.) are polyphagous pests having a high impact on vegetable and fruit crops worldwide (1). These plant-parasitic nematodes are often the most important soil pests in Mediterranean countries under both field and protected cultivations (18). On a world scale, the most economically damaging RKNs are the Mediterranean and tropical species Meloidogyne incognita (Kofoid \& White) Chitwood, $M$. javanica (Treub) Chitwood, and M. arenaria (Neal) Chitwood, which are highly polyphagous and reproduce through mitotic parthenogenesis (29). Those species are also major pests of fruit and nut production, particularly in the Prunus spp. crops such as peach, almond, and plum (26). Because chemical nematicides are prohibited in an increasing number of countries due to their side effects on the environment (2), the use of resistant cultivars is becoming a promising alternative for nematode control. Selection for RKN resistance in Prunus rootstock material has led to the characterization of several sources with more or less wide spectra $(14,15)$. Among them, some Myrobalan plum clonal accessions (Prunus cerasifera Ehr; subgenus Prunophora) express a complete-spectrum, high and heat-stable resistance to RKN (12). In this plum, resistance to all tested RKN species and, notably, to $M$. arenaria, $M$. incognita, $M$. javanica, and $M$. floridensis (an American species reproducing on peach and almond sources), is conferred by the major and completely dominant $M a$ gene $(13,21$, 28). The positional cloning strategy for $M a$ has shown that it

Corresponding author: D. Esmenjaud;

E-mail address: Daniel.Esmenjaud@sophia.inra.fr

doi:10.1094/PHYTO-01-11-0004

(c) 2011 The American Phytopathological Society belongs to the Toll interleukin-1 receptor nucleotide-binding site leucine-rich repeat class of resistance genes $(5,11)$.

Studies focused on the histological characterization of resistance to RKN have described diverse plant responses to nematode attacks ranging from strong early hypersensitive-like reactions (HLRs) leading to rapid juvenile death (Me3 in pepper) (27) to late inhibitions of the formation of the giant cells associated with an incomplete development of the nematode ( $M e 1$ in pepper [27] and $R k$ in cowpea [7]). In perennials, the few data obtained relate mainly to Prunus spp. carrying resistance to $M$. javanica in peach (24) and almond-peach (25) and to coffee carrying the Mexlmediated resistance to $M$. exigua Goeldi (3).

In Myrobalan plum, a study on the dynamics of the penetration in resistant (R) and susceptible (S) accessions carrying $M a$ (31) has been conducted. However, in this case as in other annuals and perennials, no precise histological documentation of nematode behavior in the plant during compatible and incompatible reactions is known. Here, we report a study of a detailed histological characterization of the nematode routes and of the histological mechanisms of resistance conferred by the $M a$ gene from Myrobalan plum using R (P.2175) and S (P.2032) Myrobalan plum clonal accessions. In order to validate our results in a different genetic background, an equivalent study was also conducted using $M a$-resistant and $m a$-susceptible interspecific hybrids between P.2175 and almond-peach.

\section{MATERIALS AND METHODS}

Plant material. Four clonal accessions were used in this study: P.2175 and 35 (carrying $M a$ ) and P.2032 and 253 (lacking $M a$ ). Accessions P.2175 and P.2032 are pure natural Myrobalan plum cultivars originating from Romania and southeast France, re- 
spectively, whereas accessions 253 and 35 are interspecific hybrids between P.2175 and almond-peach $(\text { Garfi } \times \text { Nemared })_{22}$ and $(\text { Garfi } \times \text { Nemared })_{15}$, respectively (Table 1). P.2175 was selected as rootstock for its high RKN resistance conferred by the $M a$ gene to the most economically damaging species $(M$. arenaria, $M$. incognita, $M$. javanica, and $M$. floridensis) $(4,21)$ and for its favorable agronomic features such as efficient vegetative propagation and graft compatibility with many fruit cultivars of peach.

Prunus plantlets obtained from in vitro, 8 -cm high, were acclimatized in perlite trays for 2 weeks and repotted into 50-ml plastic tubes containing a mix of siliceous sand, sterile silt-clay soil, and peat moss $(4: 3: 1, \mathrm{vol} / \mathrm{vol} / \mathrm{vol})$ and maintained in the growth chamber at the ambient temperature of $25^{\circ} \mathrm{C}$ with a photoperiod of $16 \mathrm{~h}$.

Animal material. Histological studies were conducted on plant material inoculated with the isolate $M$. incognita 'Morelos' (Mexico). This nematode isolate had been reared from a singlefemale egg mass. For the production of the inoculum, secondstage juveniles (J2s), <72 h old, were collected from egg masses recovered from roots of susceptible tomato 'St. Pierre' previously grown in greenhouse.

Histological experiments. Inoculation was performed around the plant collar into four holes ( $1 \mathrm{ml}$ of water per hole), $2 \mathrm{~cm}$ deep. Plants of the R accessions (P.2175 and 35) were inoculated with a water suspension containing $20,000 \mathrm{~J} 2 \mathrm{~s}$. Indeed, in a previous study (31) with equivalent plant characteristics (same age, also obtained from in vitro), mean number recovered in the total root system of plants of P.2175 inoculated with 2,500 J2s was $\approx 200 \mathrm{~J} 2 \mathrm{~s}$ per plant (for 400 estimated total apices per plant). This number of nematodes per apex was critically low for an accurate description of nematode behavior inside the roots of resistant plants; therefore, the level of 20,000 J2s per plant was chosen to allow the penetration of higher numbers of J2s. Plants of S accessions (P.2032 and 253) were inoculated with 5,000 J2s. This inoculum level was chosen on the basis of a previous methodological study (16) on the accession P.2032, with equivalent plant characteristics, showing a limited intraspecific competition between nematodes in these conditions.

Terminal root fragments, $10 \mathrm{~mm}$ long, were collected 1, 2, 3, 5, $8,12,17,23,30$, and 40 days postinoculation (dpi). After collection, root tips were washed with tap water and observed under a binocular microscope for nematode penetration and root galling. Then, infected roots were fixed overnight at $4{ }^{\circ} \mathrm{C}$ in $2 \%$ glutaraldehyde, rinsed with 'Pipes' (Sigma-Aldrich), and dehydrated by passing through a graded ethanol series at 1, 5, 30, and 50\% $(2 \mathrm{~h}$ each); $70 \%$ (overnight); and $90 \%$ ( $2 \mathrm{~h}$ ) followed by $100 \%$ in three successive independent immersions of 2,1 , and $1 \mathrm{~h}$. Infiltration and embedding were done with epoxy resin (Teknovit 7100 kit; Kulzer Friedrichsdorf, Germany). Sections, $5 \mu \mathrm{m}$ thick, were cut using a microtome (Adamas Instrument en BV, The Netherlands). Successive serial sections were shared in two equivalent groups and mounted on poly-L-lysin slides. One group of slides was stained for $30 \mathrm{~s}$ with toluidine blue in $0.1 \mathrm{M}$ sodium phosphate buffer ( $\mathrm{pH}$ 5.5), rinsed with ultrapure water, and dried. Stained reactions were examined under a Zeiss Axioplan light microscope equipped with a Nikon Cooplix 995 digital camera. In order to reveal aromatic compounds, the other group of slides was kept unstained and examined using the microscope with a UV filter set at 365-nm excitation and 420-nm emission lengths. Yellow and orange autofluorescence revealed the presence of phenolic compounds and a pale blue autofluorescence revealed the presence of lignified cells.

TABLE 1. Plant material used in the study

\begin{tabular}{lcc}
\hline Gene & Myrobalan plum & F1 interspecific material \\
\hline Resistant $(\mathrm{Mal} / \mathrm{ma})$ & P.2175 & {$\left[\mathrm{P} .2175 \times(\text { Garfi } \times \text { Nemared })_{15}\right]_{35}$} \\
Susceptible $(\mathrm{ma} / \mathrm{ma})$ & P.2032 & {$\left[\mathrm{P} .2175 \times(\text { Garfi } \times \text { Nemared })_{22}\right]_{253}$} \\
\hline
\end{tabular}

Total numbers of root fragments observed per date ranged from 6.8 (accession P.2175) to 8.7 (accession 253 ), totaling $\approx 3,000$ slides when all observation dates were considered for the four accessions.

Macroscopic reaction to nematode attacks in resistant accessions. To describe the resistance reaction to nematode attacks at the macroscopic level, accession 35 was monitored at $17 \mathrm{dpi}$ after inoculation $(20,000 \mathrm{~J} 2 \mathrm{~s})$ in comparison with uninoculated controls. Five plants of each modality were removed from the tube and their entire root system was carefully washed free of substrate. Among the entire root system, all single terminal fragments or tips (i.e., from the apex up to the junction of the fragment with another root or rootlet) were cut, recovered, and selected for further examination. In this examination, fragments with terminal buds emerged $<2 \mathrm{~mm}$ from their root extremity were considered as a single fragment or tip. In inoculated and uninoculated modalities, all fragments selected as described above were examined for their proportion of tips that harbored such lateral buds (i.e., emerged $<2 \mathrm{~mm}$ from the extremity) and their number of terminal apices per fragment. From these data, the percentage of tips with lateral buds and the mean number of buds per root tip were compared between both modalities. The same procedure was repeated at $35 \mathrm{dpi}$ in order to compare the evolution of the phenomenon.

\section{RESULTS}

Observations reported hereafter deal successively with root penetration, migration, and plant reaction to nematodes attacks. In each case, they are described first on Myrobalan plum (i.e., in both the resistant P.2175 and the susceptible P.2032 accessions) and then on the Myrobalan $\times$ almond-peach hybrids (i.e., in both the resistant 35 and the susceptible 253 accessions).

Root penetration. $\mathrm{J} 2 \mathrm{~s}$ were observed as penetrating the roots of P.2175 from $1 \mathrm{dpi}$, with a preferential location close to the meristematic region of primary root apices and a secondary location next to lateral buds (Fig. 1A and B). Penetration into the elongation zone, upward of the apical region, was less frequent. In the $S$ accession P.2032, penetration occurred in similar locations (Fig. 1C and D). In both accessions, penetrating J2s, although decreasing in numbers, were visualized up to $17 \mathrm{dpi}$. In the $\mathrm{R}$ or $\mathrm{S}$ interspecific accessions, locations of penetration were equivalent to pure Myrobalan plum (data not shown). Several nematodes grouped under the first cell layers were observed, illustrating that penetration often occurred in only a few points of the root surface (Fig. 1E and F).

Migration. In the roots of the resistant accession P.2175, the $\mathrm{J} 2 \mathrm{~s}$ that had just gone through the epidermis and reached the cortical region always oriented themselves downward, in the direction of the root tip (Fig. $1 \mathrm{G}$ and $\mathrm{H}$ ). We observed that this longitudinal migration to the apical meristematic cells could occur more or less deeply in the cortical tissue but was always limited by the endodermis (Fig. 1H and P). Although J2s were shown to migrate intercellularly, needing a channel for this corresponding approximately to their diameter, they occasionally created big spaces between cell layers. This was particularly marked when the route opened by a first juvenile was used by several others (a frequent observation) that were located either in a single file or more crowded all together (Fig. 1J and K). When $\mathrm{J} 2 \mathrm{~s}$ reached the meristematic apical region of the roots, they turned around in the central part of the apex (Fig. 1H, L, and N, with details of $\mathrm{J} 2 \mathrm{~s}$ rotation in $\mathrm{M}$ and $\mathrm{O}$ ) and migrated upward between the cells toward the differentiated vascular cylinder (Fig. 1I and Q). The first J2s reaching the vascular cylinder were observed at 3 dpi. However, a complete migration of J2s up to the differentiated region of the stele was not always observed. In many cases, nematodes remained in the meristematic terminal region and were surrounded by a disrupted structure of this root zone (Fig. 1P and Q). 
In the roots of the susceptible accessions P.2032 and 253, the early migration route of the motile $\mathrm{J} 2 \mathrm{~s}$ appeared equivalent to that of the resistant accessions P.2175 and 35, with a downward migration into the cortex, a rotation in the meristematic apical region, and an upward colonization of the vascular cylinder. Nevertheless, in $\mathrm{S}$ accessions, destruction of the tissues was never observed around moving nematodes.

Compatible interaction in susceptible accessions. In P.2032, external macroscopic observations of roots revealed the first galls at 5 dpi (Fig. 2A). At that date, observations of gall sections showed swollen juveniles in the vascular cylinder which were already inducing feeding sites around their head. However, there still existed some J2s which had not yet reached the vascular cylinder. At $8 \mathrm{dpi}$, the galls were large and well developed as a result of the hypertrophy of the giant cells and the hyperplasia of surrounding cells. At $17 \mathrm{dpi}$, all of the developmental stages of the nematodes (J2, swollen J2, J3, J4, and female) were simultaneously present in the galls (Fig. $2 \mathrm{C}$ to $\mathrm{F}$ ). The first female with
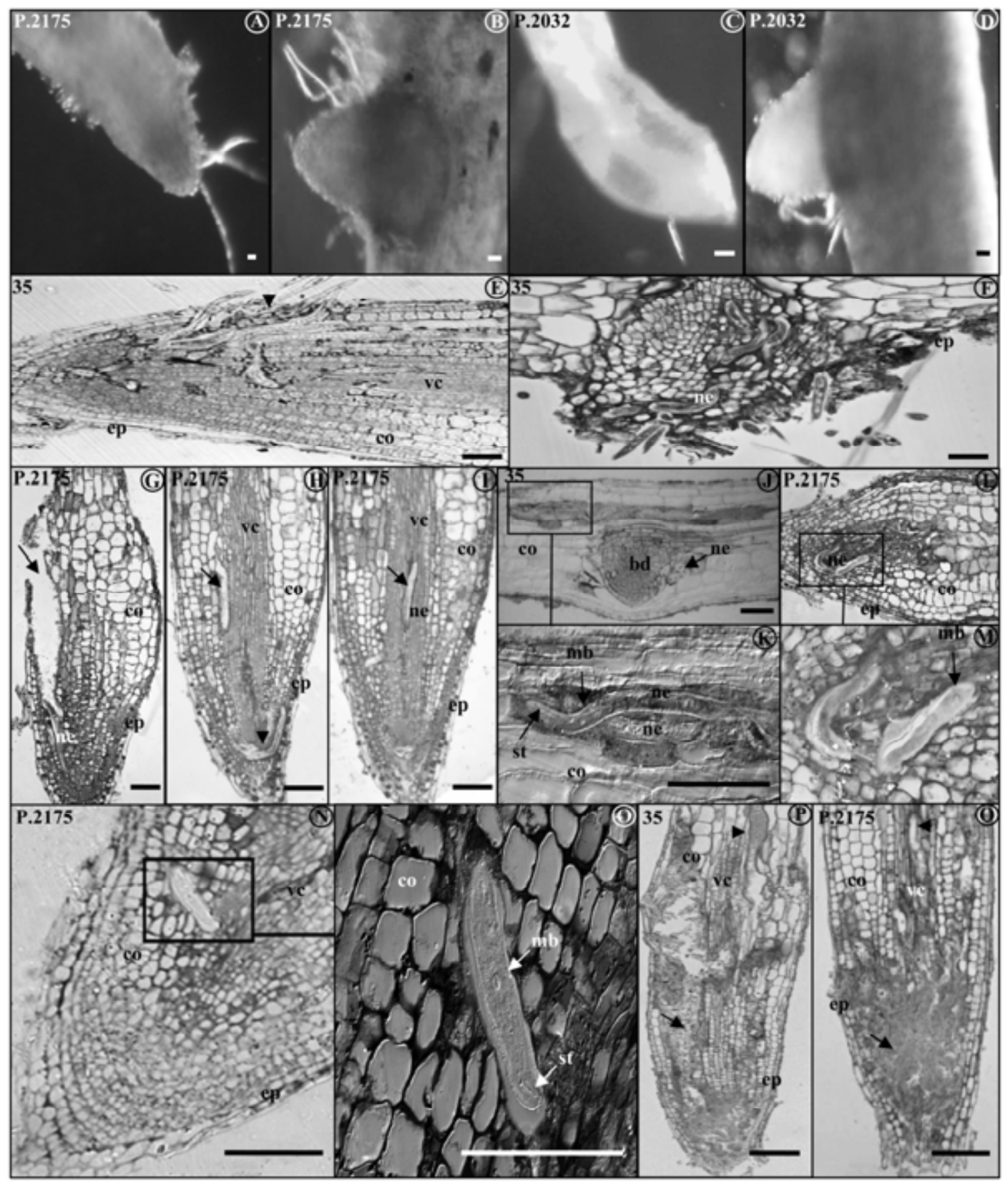

Fig. 1. Itinerary of second-stage juveniles (J2s) in the resistant (P.2175 and 35) and susceptible (P.2032) accessions. A and C, Apical penetration. B and D, Penetration next to lateral buds. E and F, Penetration in the same points either in the apical area (arrow head) or in the bud, respectively. G to I, Different steps of the migration at 3 days postinoculation (dpi). G, J2 having migrated in the cortex. $\mathbf{H}, \mathbf{J} 2$ channel in the inner cortex limited by the endodermis (arrow); J2 leaving the cortex and penetrating the meristematic apical region (arrow head) before turning upward in the direction of the vascular cylinder. I, $\mathbf{J} 2$ in the vascular cylinder (the arrow points the nematode head). J, Two J2s migrating intercellularly along the same route ( $8 \mathrm{dpi}$ ). $\mathbf{K}$, Magnification of J. $\mathbf{L}$ and $\mathbf{N}$, J2 moving from the cortex into the apical meristematic region (17 dpi). $\mathbf{M}$ and $\mathbf{O}$, Magnification of $\mathrm{L}$ and $\mathrm{N}$, respectively. $\mathbf{P}$ and $\mathbf{Q}$, Several $\mathbf{J} 2 \mathrm{~s}$ causing disruption of tissues in both $\mathbf{P}$, the cortical and meristematic region and $\mathbf{Q}$, the meristematic region (arrows) at $8 \mathrm{dpi}$. Arrowheads point to the longitudinal channels caused by nematodes during migration in the $\mathbf{P}$, cortex and $\mathbf{Q}$, vascular cylinder; ep $=$ epidermis, $c o=$ cortex, vc $=$ vascular cylinder, ne $=$ nematode, $\mathrm{mb}=$ median bulb, $\mathrm{st}=\mathrm{stylet}, \mathrm{bd}=\mathrm{bud}$. Bars $=100 \mu \mathrm{m}$ 
an attached egg sac was observed at $23 \mathrm{dpi}$ (Fig. $2 \mathrm{~F}$ and G). Eggs were visible on the root surface in the protective, gelatinous matrix (Fig. 2H). At $40 \mathrm{dpi}$, the presence of the filiform males was detected in the tissues (Fig. 2I).

HLR in resistant accessions. Examination of $\approx 920$ root sections of the accessions P.2175 and 35 showed that all J2s recovered inside the roots remained filiform (body diameter of 12 to $15 \mu \mathrm{m})$ and that there was no formation of giant cells. Microscopic observations of stained root sections revealed darkblue color characteristic of an HLR around the nematode at different dates. The earliest HLR was characterized at 3 dpi in our study (Fig. 3A and B). Such reactions occurred in either the vascular cylinder (Fig. 3A and $\mathrm{G}$ ), the meristematic or bud regions (Fig. 3C and E), or the cortex (Fig. 3I). The intensity of staining seemed to be higher at later dates (40 dpi) (Fig. 3I and J). When root sections were examined under UV light, the yellow or orange autofluorescence (Fig. 3D, F, and K), exhibiting the presence of aromatic compounds, was seen within the cells and in cell walls. In our figures, we could observe clear signs of nematode death at 23 dpi (Fig. $3 \mathrm{G}$ and $\mathrm{H}$ ).

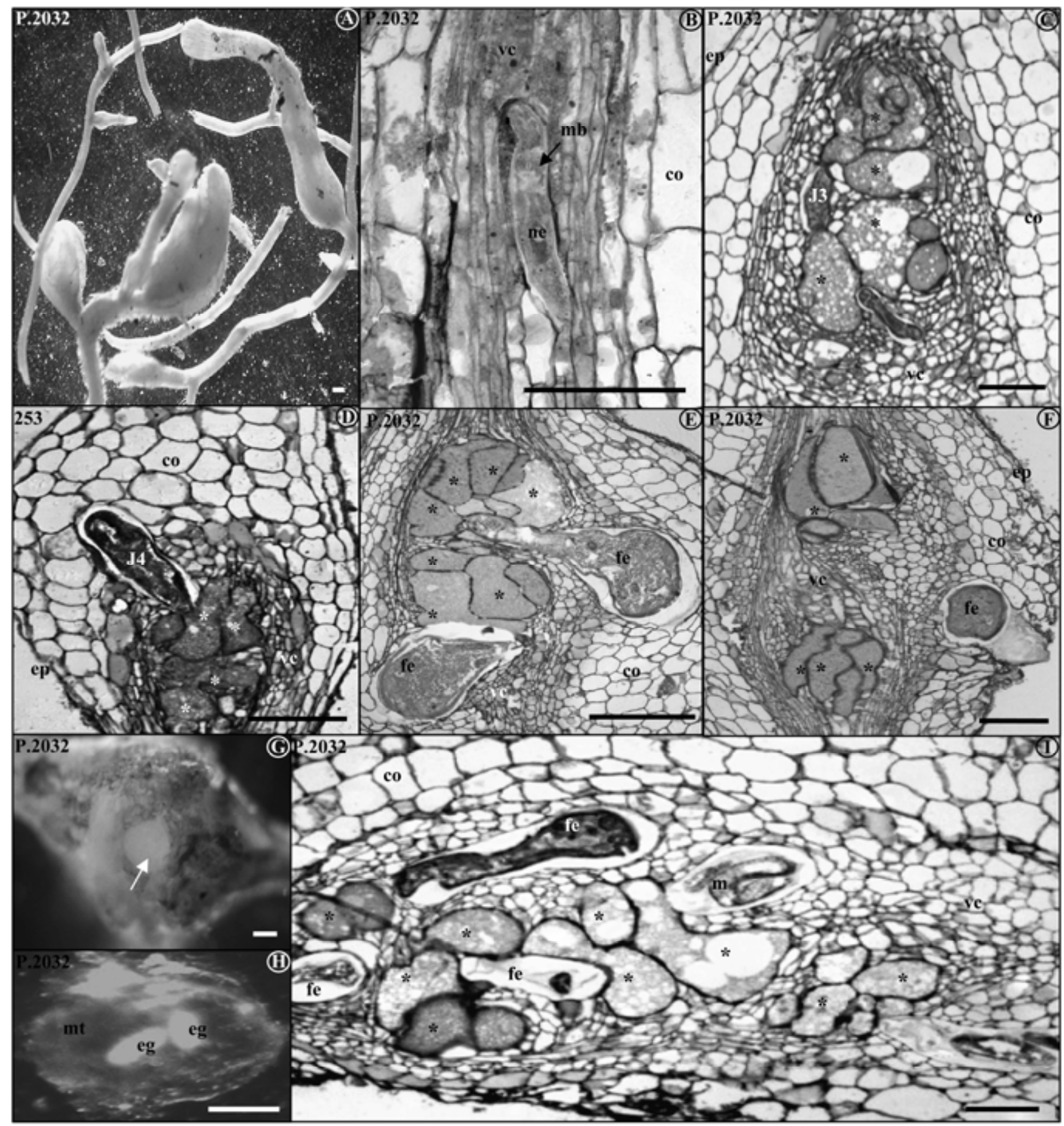

Fig. 2. Compatible interaction in susceptible accessions (P.2032 and 253). A, Galls on apices at 5 days postinoculation (dpi). B, Swollen second-stage juvenile (J2) in the stele at 3 dpi. $\mathbf{C}$ to $\mathbf{F}$, Sections of galls showing feeding sites with different developmental stages of the nematodes at 17 dpi: C, J3; D, J4; E, young female; and $\mathbf{F}$, female with attached egg mass. G, Posterior end of female (arrow) emerged at the gall surface at 23 dpi. H, Gelatinous matrix containing eggs (separated from the egg mass) at 23 dpi. I, Feeding site with vacuolated giant cells and females at 40 dpi. Note filiform male still coiled within the J4 cuticle; ep = epidermis, $\mathrm{co}=$ cortex, $\mathrm{vc}=$ vascular cylinder, ne $=$ nematode, $\mathrm{mb}=$ median bulb, $\mathrm{st}=$ stylet, $\mathrm{fe}=$ female, $\mathrm{mt}=$ matrix, eg $=\mathrm{egg}, \mathrm{m}=$ male, $*=$ giant cell. Sections were stained with toluidine blue. Bars $=100 \mu \mathrm{m}$ (except $\mathrm{A}, \mathrm{G}$ and $\mathrm{H}$, where bars $=500 \mu \mathrm{m}$ ). 
Initiation of lateral buds and development of replacement lateral roots at the apices of resistant accessions under nematode attacks. In $M a$-resistant accessions, observations of development of roots in apical regions consecutive to nematode attacks showed the emergence of newly formed lateral roots from buds formed just upward of the apices (Fig. 3L to P). These subterminal lateral roots emerged from the stele as a consequence of disorganization of tissues observed in the meristematic terminal regions (Fig. 3Q to S). Newly formed lateral roots were either single or double (symmetrical). When the root was single, it took

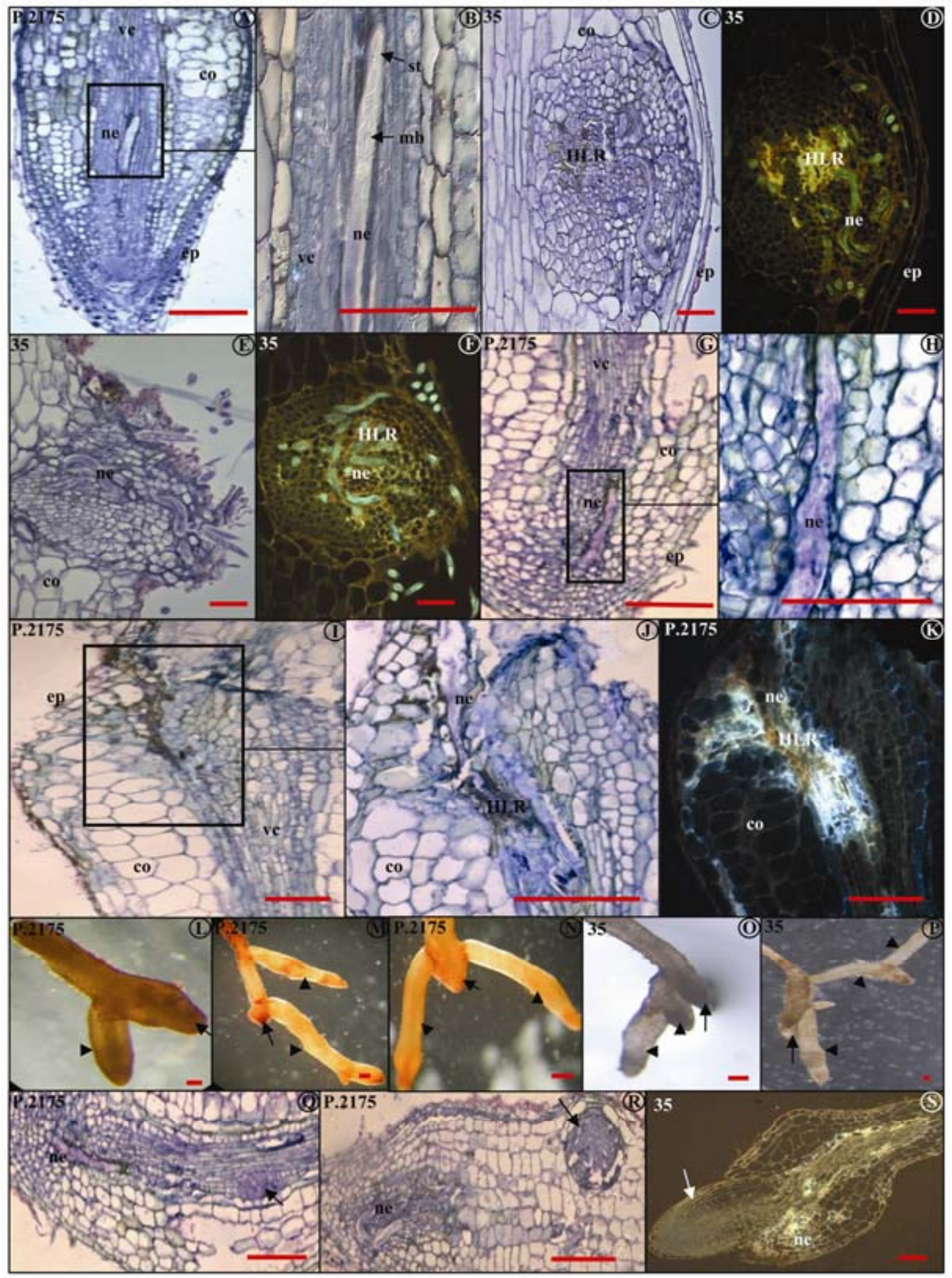

Fig. 3. Incompatible interaction in resistant accessions (P.2175 and 35). A, C, E, G, and I, Sections stained with toluidine blue showing hypersensitive-like reactions (HLRs) associated with second-stage juveniles (J2s). B, H, and J, Magnification of A, G, and I, respectively. D, F, and K, Unstained sections observed under UV showing yellow and orange fluorescence illustrating HLR around J2s. L to P, Lateral roots neoformed (arrowheads) near damaged apices (arrows). Q, $\mathbf{R}$, and S, Sections showing damaged meristematic apical tissues (arrow) and correlative emergence of lateral roots (section S is unstained and observed under $\mathrm{UV})$; ep $=$ epidermis, $c 0=$ cortex, $\mathrm{vc}=$ vascular cylinder, $\mathrm{ne}=$ nematode, $\mathrm{mb}=$ median bulb, $\mathrm{st}=$ stylet. Bars $=100 \mu \mathrm{m}($ except $\mathrm{L}$ to $\mathrm{P}$, where bars $=500 \mu \mathrm{m})$. 
the same growth direction as the damaged root and appeared to be replacing it. Numerical evaluation of root development showed that the proportion of tips with lateral buds is highly significantly different (more than twice) in the inoculated plants in comparison with the negative controls $\left(\chi^{2}=75.2 ; P<0.001\right)$. The number of lateral buds per root tip is also highly significantly different, being more than doubled in the presence of the nematodes $\left(\chi^{2}=49.4\right.$; $P<0.001]$ (Table 2). Moreover, values of neoformation of roots are equivalent after 17 and 35 days $\left(\chi^{2}=0.26\right.$ and 0.28 , respectively, for proportion of tips with lateral buds and number of buds per root tip) (Table 2).

\section{DISCUSSION}

The first aim of this study was to compare RKN penetration and subsequent development in $M a$-resistant and $m a$-susceptible accessions of Prunus spp. In the four tested accessions, we observed $\mathrm{J} 2 \mathrm{~s}$ initiating their penetration $<48 \mathrm{~h}$ after inoculation into the soil. Although their numbers decreased, penetrating nematodes were observed up to $17 \mathrm{dpi}$, stating that motile J2s can survive in the substrate for more than 2 weeks. Our results, obtained in both Myrobalan plum and interspecific genetic backgrounds, are in agreement with previous data from Voisin et al. (31), in which equivalent numbers of $M$. arenaria were recovered in the roots of the susceptible P.2032 and resistant P.2175 accessions at 1 and 2 dpi. Consequently, we confirm here that the $M a$ gene does not induce an early resistance phenomenon due to a physical or chemical barrier to penetration $(6,19)$. This situation is contrary to CM334 pepper (carrying the Me7 gene), in which J2s are preferably blocked in the epidermal layer of cells (27) and might trigger an active early post-penetration biochemical defense mechanism.

We have shown that, in material carrying $M a$ as well as in material lacking it, penetration occurred preferentially in the apical region or in the vicinity of the lateral buds (i.e., in areas where cells are the youngest and are expected to facilitate nematode mobility). Moreover, penetration sites were shown to be often shared by several juveniles which afterwards used the same routes inside the plant. After penetration, J2s migrated intercellularly, separating cells at the middle lamella in the cortical tissue. This intercellular migration of Meloidogyne spp. described in many plant species $(9,30)$ is confirmed here. This process appears to include both mechanical forces and enzymatic secretions from the nematodes (32). In both $\mathrm{R}$ and $\mathrm{S}$ accessions, we have observed that, once nematodes had penetrated the terminal zone, they never moved transversally in the roots through the endodermis and the pericycle (to directly reach the protoxylem and protophloem cells where they should become sedentary and fix to initiate their feeding site) (19). Our hypothesis is that, because of the presence of specific structures called the casparian strip reinforcing the radial and transversal walls of endodermal cells (10), J2s are unable to dissolve the middle lamella between these cells for direct access to the vascular cylinder. Thus, they might be obliged to migrate first downward in the direction of the meristematic region, turn in the opposite direction, and, last, to move upward in the direction of the vascular cylinder. Even though the same route has been described in the compatible reaction between $M$. incognita and Arabidopsis thaliana using immunolabeling techniques at the cellular level (17), we have shown here the first example of this nematode behavior in an accession carrying a resistance gene.

In resistant clones (P.2175 and 35), the juveniles neither swelled nor developed but remained filiform. This shows that the $M a$ gene completely prevented the fixation of the motile $\mathrm{J} 2 \mathrm{~s}$ in cells from the different plant tissues through which they move and, particularly, from the vascular cylinder, thus depriving it of nutrients and inhibiting further development into inflated stages. Thus, in this plum gene, we observed a situation different from Malo (24) with M. javanica, who reported the presence of thirdstage juveniles inducing incomplete giant cells at 4 dpi in the resistant peach rootstocks 'Okinawa' and 'Nemaguard'. Identical responses of partial nematode development and incomplete giant cell formation were also described by Marull et al. (25) in interspecific Prunus material derived from Nemaguard. The histological study on the Mex-1 gene conferring resistance in coffee (Coffea arabica) to M. exigua also showed that $\mathrm{J} 2$ s swelled to $\mathrm{J} 3$ to J4 and initiated their feeding sites at 10 to $14 \mathrm{dpi}$ (3).

Within roots of the susceptible P.2032 and 253 accessions, J2s induced giant cells among the vascular cylinder. As classically described, the giant cells contained highly condensed cytoplasm and enlarged nuclei (with marked nucleoli) resulting from mitosis uncoupled from cytokinesis $(8,19)$. Concurrent swelling and division of cells around the head of the nematode led to the formation of galls and the distorted root structure characteristic of Meloidogyne spp. infection. Our data at $25^{\circ} \mathrm{C}$ established that, from the motile $\mathrm{J} 2$ stage (inoculation date) and the development of the nematode up to the detection of the first female lasted $<17$ days, and up to the first female carrying an egg mass lasted $<23$ days. Egg masses, released on the root surface in a protective gelatinous matrix, were less apparent than in tomato, presumably because of the rigidity of tissues due to the synthesis of lignin.

The present histological study clearly showed that resistance conferred by the $M a$ gene is associated with cell necroses (arresting the nematode development) and the corresponding HLR phenotypes occurring in either the vascular cylinder, the meristematic apical or bud regions, or the cortex. Differential staining with toluidine blue revealed dark-blue and blue-green coloration of HLR cell compounds and suggested accumulation of phenolics (23). Under UV light, some compounds emitted yellow-orange fluorescence with a lower intensity than in resistant pepper CM334 (27), in which a high content of phenolics such as chlorogenic acid has been detected. In resistant accessions P.2175 and 35 , the first signs of cellular necrosis were localized in the vascular cylinder at $3 \mathrm{dpi}$. Further investigations are required in order to understand more accurately the underlying mechanisms involved in the HLR mediated by the Ma gene in Prunus spp. at both cellular and molecular levels.

TABLE 2. Effect of nematode attacks on lateral root bud emergence in the resistant accession 35

\begin{tabular}{|c|c|c|c|}
\hline \multirow[b]{2}{*}{ Effect } & \multicolumn{2}{|c|}{ Inoculated plants ${ }^{\mathrm{a}}$} & \multirow[b]{2}{*}{ Uninoculated control plants } \\
\hline & 17 dpi & 35 dpi & \\
\hline Percent tips with lateral buds (number of tips) & $76.4(178)^{\mathrm{c}, \mathrm{d}}$ & $74.9(199)^{\mathrm{d}}$ & $31.2(189)^{\mathrm{c}}$ \\
\hline Mean number of buds per root tip ${ }^{\mathrm{e}}$ & $1.49^{\mathrm{f}, \mathrm{g}}$ & $1.42^{\mathrm{g}}$ & $0.71^{\mathrm{f}}$ \\
\hline \multicolumn{4}{|c|}{$\begin{array}{l}\text { a Abbreviation: dpi }=\text { days postinoculation. } \\
\text { b Percent }=\text { number of apices harboring lateral buds emerging less than } 2 \mathrm{~mm} \text { from the extremity/total number of apices. } \\
\text { c } \chi^{2}=75.2(P<0.001) \\
\text { d } \chi^{2}=0.26 \\
\text { e Total number of lateral buds (as considered above)/total number of apices. } \\
\text { f } \chi^{2}=49.4(P<0.001) \\
\text { g } \chi^{2}=0.28\end{array}$} \\
\hline
\end{tabular}


Another interesting feature identified in resistant material was the emergence of new lateral roots near the infected root tips. Malo (24) also reported the same feature on resistant cultivars of peach. We could show that each of the criteria "percentage of tips with lateral buds" and "mean number of buds per root tip" were increased in infected plants. This rapid induction of lateral roots consecutive to the nematode attack, by contributing to the replacement of damaged apices, is involved in the overall resistance of the plant against the RKNs. Moreover, values of these criteria were equivalent after 17 and 35 days, which suggests that plant response to nematode effect reaches a maximum before or at 17 days. This is in agreement with our results that showed that $\mathrm{J} 2 \mathrm{~s}$ penetrated up to this date, although in decreasing numbers, and, consequently, their destructive activity is expected to be lower after it.

In Arabidopsis, this ability to create new lateral roots has been shown to require a repolarization of auxin (IAA) by carriers termed PIN proteins (20). These carriers cycle between the basal and lateral sides of the cell: this polarity change and subsequent formation of new axes of development consecutive to root cell division is under the control of the protein VPS29 from the "retromer" complex. An overexpression of the ROP2 signal transmitter in cells accumulating auxins (22) might also be linked to the formation of lateral meristems. In Prunus spp., homologous genes of these proteins presumably exist and the characterization of their expression in the root tissues carrying the $M a$ gene would provide evidence of their involvement in the lateral root formation consecutive to nematode attacks.

\section{LITERATURE CITED}

1. Abad, P., Gouzy, J., Aury, J. M., et al. 2008. Genome sequence of the metazoan plant-parasitic nematode Meloidogyne incognita. Nat. Biotechnol. 26:909-915.

2. Abawi, G. S., and Widmer, T. L. 2000. Impact of soil health management practices on soilborne pathogens, nematodes and root diseases of vegetable crops. Appl. Soil Ecol. 15:37-47.

3. Anthony, F., Topart, P., Martinez, A., Sliva, M., and Nicole, M. 2005. Hypersensitive-like reaction conferred by Mex-1 resistance gene against Meloidogyne exigua in coffee. Plant Pathol. 54:476-482.

4. Cetintas, R., Kaur, R., Brito, J. A., Mendes, M. L., Nyczepir, A. P., and Dickson, D. W. 2007. Pathogenicity and reproductive potential of Meloidogyne mayaguensis and M. floridensis compared with three common Meloidogyne spp. Nematropica 37:21-31.

5. Claverie, M., Dirlewanger, E., Bosselut, N., Van Ghelder, C., Voisin, R., Kleinhentz, M., Lafargue, B., Abad, P., Rosso, M. N., Chalhoub, B., and Esmenjaud, D. 2004. The $M a$ gene for complete-spectrum resistance to Meloidogyne spp. in Prunus is a TNL with a huge repeated C-terminal post LRR region. Plant Physiol. DOI:10.1104/pp.111.176230.

6. Cook, R., and Evans, K. 1987. Resistance and tolerance. Pages 179-231 in: Principles and Practice of Nematode Control in Crops. R. H. Brown and B. R. Kerry, eds. Academic Press, Marrickville, NSW Australia.

7. Das, S., DeMason, D. A., Ehlers, J. D., Close, T. J., and Roberts, P. A. 2008. Histological characterization of root-knot nematode resistance in cowpea and its relation to reactive oxygen species modulation. J. Exp. Bot. 59:1305-1313.

8. Davis, E. L., Hussey, R. S., Mitchum, M. G., and Baum, T. J. 2008. Parasitism proteins in nematode-plant interactions. Curr. Opin. Plant Biol. 11:360-366.

9. Endo, B. Y., and Wergin, W. P. 1973. Ultrastructural investigation of clover roots during early stages of infection by the root knot nematode Meloidogyne incognita. Pages 143-152 in: An Advanced Treatise on Meloidogyne. No. 1. J. N. Sasser and C. C. Carter, eds. North Carolina State University Graphics, Raleigh.

10. Esau, K. 1965. The root. Pages 481-538 in: Plant Anatomy, 2nd ed. John Wiley \& Sons, New York.

11. Esmenjaud, D., and Dirlewanger, E. 2007. Genome mapping and molecular breeding in plum. Pages 119-136 in: Genome Mapping and Molecular Breeding in Plants. No. 4. C. Kole, ed. Springer Verlag,
Heidelberg, Germany.

12. Esmenjaud, D., Minot, J. C., and Voisin, R. 1996. Effect of durable inoculum pressure and high temperature on root galling, nematode numbers and survival of Myrobalan plum genotypes (Prunus cerasifera Ehr.) highly resistant to Meloidogyne spp.. Fundam. Appl. Nematol. 19:85-90.

13. Esmenjaud, D., Minot, J. C., Voisin, R., Bonnet, A., and Salesses, G. 1996. Inheritance of resistance to the root-knot nematode Meloidogyne arenaria in Myrobalan plum. Theor. Appl. Genet. 92:873-879.

14. Esmenjaud, D., Minot, J. C., Voisin, R., Pinochet, J., and Salesses, G. 1994. Inter- and intraspecific resistance variability in Myrobalan plum, peach and peach-almond rootstocks using 22 root-knot nematode populations. J. Am. Soc. Hortic. Sci. 119:94-100.

15. Esmenjaud, D., Minot, J. C., Voisin, R., Pinochet, J., Simard, M. H., and Salesses, G. 1997. Differential response to root-knot nematodes in Prunus species and correlative genetic implications. J. Nematol. 29:372-380.

16. Esmenjaud, D., Minot, J. C., Voisin, R., Salesses, G., Poupet, R., and Onesto J.P. 1993. Assessment of a method using plantlets grown previously from in vitro for studying resistance of Prunus cerasifera Ehr. (Myrobalan plum) to Meloidogyne spp.. Nematropica 23:41-48.

17. Gravato-Nobre, M. J., McClure, A., Dolan, L., Galder, G., Davies, K. G., Mulligan, B., Evans, K., and Von Mende, N. 1999. Meloidogyne incognita surface antigen epitopes in infected Arabidopsis roots. J. Nematol. $31: 212-223$.

18. Greco, N., and Esmenjaud, D. 2004. Management strategies for nematode control in Europe. Pages 33-43 in: Nematology Monographs and Perspectives. Brill. No. 2. D. J. Hunt and R. N. Perry, eds. Leiden, Boston.

19. Huang, C. S. 1985. Formation, anatomy and physiology of giant cells induced by root-knot nematodes. Pages 155-164 in: An Advanced Treatise on Meloidogyne. No. 1. J. N. Sasser and C. C. Carter, eds. North Carolina State University Graphics, Raleigh.

20. Jallais, Y., Santambrogio, M., Rozier, F., Fobis-Loisy, I., Miège, C., and Gaude, T. 2007. The retromer protein VPS29 links Cell polarity and organ initiation in plants. Cell 130:1057-1070.

21. Lecouls, A. C., Salesses, G., Minot, J. C., Voisin, R., Bonnet, A., and Esmenjaud, D. 1997. Spectrum of the $M a$ genes for resistance to Meloidogyne spp. in Myrobalan plum. Theor. Appl. Genet. 95:1325-1334.

22. Li, H., Shen, J. J., Zheng, Z. L., Lin, Y., and Yang, Z. 2001. The Rop GTPase switch controls multiple developmental processes in Arabidopsis. Plant Physiol. 126:670-684.

23. Locquin, M., and Langeron, M. 1978. Manuel de Microscopie. Masson, Paris.

24. Malo, S. E. 1967. Nature of resistance of 'Okinawa' and 'Nemaguard' of the root-knot Nematode Meloidogyne javanica. Proc. Am. Sci. Hortic. Res. 90:39-46.

25. Marull, J., Pinochet, J., Felipe, A., and Cenis, J. L. 1994. Resistance verification in Prunus selections to a mixture of 13 Meloidogyne isolates and resistance mechanisms of a peach-almond hybrid to Meloidogyne javanica. Fundam. Appl. Nematol. 59:1305-1313.

26. Nyczepir, A. P., and Esmenjaud, D. 2007. Nematodes. Pages 505-535 in: The Peach Botany Production and Uses. D. R. Layne and D. Bassi, eds. CABI, Wallingford, Oxon, UK.

27. Pegard, A., Brizzard, G., Fazari, A., Soucaze, O., Abad, P., and DjianCaporalino, C. 2005. Histological characterization of resistance to different root-knot nematode species related to phenolics accumulation in Capsicum annuum. Phytopathology 95:159-165.

28. Rubio-Cabetas, M. J., Minot, J. C., Voisin, R., Esmenjaud, D., Salesses, G., and Bonnet, G. 1999. Response of the Ma genes from Myrobalan plum to Meloidogyne hapla and M. mayaguensis. HortScience 34:12661268.

29. Triantaphyllou, A. C. 1985. Cytogenetics, cytotaxonomy and phylogeny of root-knot nematodes. Pages 113-126 in: An Advanced Treatise on Meloidogyne. No.1. J. N. Sasser and C. C. Carter, eds. North Carolina State University Graphics, Raleigh.

30. Trudgill, D. L., and Blok, V. C. 2001. Apomictic, polyphagous root-knot nematodes: Exceptionally successful and damaging biotrophic root pathogens. Annu. Rev. Phytopathol. 39:53-77.

31. Voisin, R., Minot, J. C., and Esmenjaud, D. 1999. Penetration, development and emigration of juveniles of the nematode Meloidogyne arenaria in Myrobalan plum (Prunus cerasifera) clones bearing the $\mathrm{Ma}$ resistance genes. Eur. J. Plant Pathol. 105:103-108.

32. Williamson, V. M., and Hussey, R. S. 1996. Nematode pathogenesis and resistance in plants. Plant Cell 8:1735-1745. 